DOI: $10.4274 /$ tpa.46.83

\title{
Hashimoto tiroiditli hastalarımızın özellikleri
}

\section{Characteristics of our patients with Hashimoto thyroiditis}

\author{
Elif Özsu, Rahime Gül Yeşiltepe Mutlu, Filiz Çizmeci, Şükrü Hatun \\ Kocaeli Üniversitesi Tıp Fakültesi Çocuk Sağı̆̆ı ve Hastalılkarı Anabilim Dalı, Pediatrik Endokrinoloji Birimi, Kocaeli, Türkiye
}

Özet

Amaç: Hashimoto tiroiditi (HT) çocuk ve ergenlerdeki guatrın ve edinsel hipotiroidin en sık sebebidir. Bu çalışmada HT ile başvuran hastalarımızın klinik, epidemiyolojik ve laboratuvar bulgularını sunmayı amaçladık.

Gereç ve Yöntem: Kliniğimizde Ocak 2004- Aralık 2009 yılları arasında takip edilen 106 hasta değerlendirildi. Hastalar tiroid işlevlerine göre dört gruba ayrıldı.

Bulgular: Tüm hastaların \%78'i kız olup, HT kızlarda 3,6 kat daha fazla saptandı. Ortalama tanı yaşı 11,5 $\pm 2,8$ yıl idi. Tanı anında hastalarımızın \%42,5'i ötiroid, \%24,5'i subklinik hipotiroidizm, \%29'u aşikar hipotiroidizm ve \%2,8'i subklinik hipertiroidizm tablosunda idi. En sık başvuru şikayeti \%46 ile guatr iken, \%26'sında gelişme geriliği, \%13'ünde kilo alımı, \%6,6 kilo kaybı, \%5,5'inde ise sinirlilik idi. Aile öyküsü olguların \%36'sında mevcut olup, \%26,4'ünde ise başka bir otoimmün hastalık saptandı. En sık eşlik eden otoimmün hastalık tip 1 Diyabetes Mellitus (DM) idi. İki olguda da çölyak, tip 1 DM ve HT birlikte izlendi. Vitiligo bir hastada saptandı.

Çıkarımlar: Otoimmün hastalıklarda artmış sıklığı nedeni ile HT, olgularda belli aralıklarla araştırılmalıdır. (Türk Ped Arş 2011; 46: 252-5)

Anahtar sözcükler: Ergen, hashimoto tiroidit, otoimmünite

\section{Summary}

Aim: Hashimoto's thyroiditis (HT) is the most common cause of goiter and acquired hypothyroidism in children and adolescents. We aimed to investigate the clinical manifestations, epidemiological and laboratory characteristics of the patients with HT.

Material and Method: We reviewed files of 106 children and adolescents with HT followed in the Department of Pediatric Endocrinology, between january 2004 and december 2009. The patients were classified in to four groups with respect to their thyroid functions.

Results: Female patients constituted $78 \%(n=83)$ of all patients. Hashimoto's thyroiditis was 3.6 times more common in females. Mean age at diagnosis was $11.5 \pm 2.8$ years. At the time of diagnosis $42.5 \%$ of patients ( $\mathrm{n}: 45)$ were euthyroid, $24.5 \%$ ( $\mathrm{n}: 26$ ) had subclinical hypothyroidism, $29 \%(n: 31)$ had overt hypothyroidism and $2.8 \%(n: 3)$ had subclinical hyperthyroidism. The common complaints leading to referral were goitre in $49(46 \%)$ children. Twenty six percent of all patients were admitted with growth retardation, $13 \%$ with weight gain $6.4 \%$ with weight loss, and $5.5 \%$ with nervousness. Family history for thyroid disease was positive in 38 (35.8\%) children. There were 28 patients (26.4\%) in whom the disease was associated with some other autoimmune diseases. The most common concomitant autoimmune disease was type 1 diabetes mellitus (DM) (21.7\%). Two patients (1.9\%) had both type 1 diabetes mellitus and celiac disease and one patient (1\%) had vitiligo.

Conclusions: We must test for HT in autoimmune disease patients periodically because of increased risk. (Turk Arch Ped 2011; 46: 252-5)

Key words: Hashimoto Thyroiditis, autoimmunity, adolescent

\section{Giriş}

Hashimoto tiroiditi çocuk ve ergenlerdeki guatrın ve kazanılmış hipotiroidinin en sık sebebidir. Değişik derecelerde hücresel ve hümoral immün yanııın rol aldığı, tiroid bezinin lenfositik enfiltrasyonu ile belirgin; "apopitozun" araclık ettiği tiroid hücre ölümü ile sonuçlanan organa özgül bir otoimmün hastalıktır (1-3).
Kızlarda erkeklere göre 2-4 kat daha sık izlenmektedir. En sık görülen klinik bulgusu guatr ve boy kısalığıdır. Ergenlik döneminde pik yapmaktadır. Hastalar başvuru anında bulgu veren hipotiroidi, belirgin hipotiroidi ve nadiren hipertiroidi kliniği ile başvurabilirler (3-4). Biz bu yazıda kliniğimizde izlenen Hashimoto tiroiditli hastaların klinik, epidemiyolojik ve laboratuvar bulgularını sunmayı amaçladık.

Yazışma Adresi/Address for Correspondence: Dr. Elif Özsu, Kocaeli Üniversitesi Tıp Fakültesi Çocuk Sağlığı ve Hastalıkları Anabilim Dalı Pediatrik Endokrinoloji Birimi, Kocaeli, Türkiye E-posta: elozdr@gmail.com Geliş Tarihi/Received: 12.12.2010 Kabul Tarihi/Accepted: 31.03.2011

Türk Pediatri Arşivi Dergisi, Galenos Yayınevi tarafindan basılmıştır. / Turkish Archives of Pediatrics, published by Galenos Publishing 


\section{Gereç ve Yöntem}

Kliniğimizde Ocak 2004- Aralık 2009 yılları arasında takip edilen yaşları 4,6-17,5 yıl arasında değişen 106 hasta değerlendirildi. Hastaların yaş, cinsiyet, başvuru şikayeti, aile öyküsü, klinik ve laboratuvar bulguları kaydedildi. Tirotropin (TSH), tiroid hormon (triiyodotronin ve tiroksin) düzeyleri ve otoantikorlar (anti-tiroglobulin ve anti-peroksidaz) "kemülisans" yöntemle ölçüldü. Tiroid ultrasonografileri "Ultrasound Toshiba Prime Ultrasound" aleti ile 5 Mhz'lik problar kullanılarak yapıldı. İdrar iyot düzeyi ölçülemedi. Gerekli olgularda tiroid sintigrafisi "Philips Adac" ile teknesyum 99-m kullanılarak çekildi. Hastalar tiroid işlevlerine göre dört gruba ayrıldı: Ötiroid (hem sT4, hem TSH düzeyi normal sınırlarda olanlar), subklinik hipotirodi (sT4 düzeyi normalken, TSH düzeyinin yüksek olması), belirgin hipotiroidi (sT4 seviyesi düşükken, TSH seviyesinin yüksek olması) ve subklinik hipertiroidi (sT4 seviyesi normalken, TSH seviyesinin baskılanmış olması).

İstatistiksel analiz için SPSS (sürüm 13) kullanıldı. Gruplar arasındaki farklııklar değişkenli testler için student t testi, değişkenli olmayan testler için Mann-Whitney U testi kullanılarak saptandı. Sıklıklar ki kare testi ile karşılaştıııldı. İstatistiksel anlamlılık için $p<0,05$ kabul edildi.

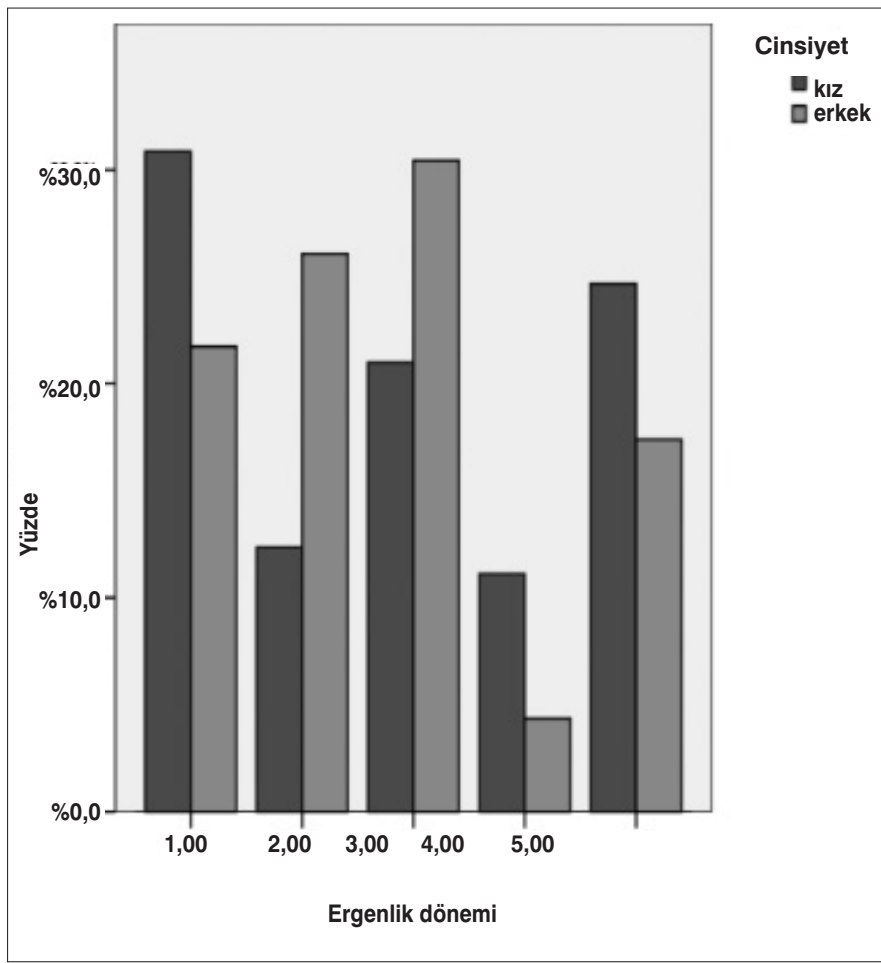

Grafik 1. Hastaların yaşlara göre dağıımı

\section{Bulgular}

Hastaların \%78'i kız (n:83), \%22'si (n:23) erkekti. Hashimoto tiroiditi kızlarda 3,6 kat daha fazla saptandı. Tanı anında hastaların yaş ortalaması 11,5 $\pm 2,8$ yıl olup, \%72'si (n:77) pubertaldi (Grafik 1-2).

En sık başvuru şikayeti guatr (\%46) iken boy kısalı̆ı̆ (\%26), kilo artı̧̧ı $(\% 13)$, sinirlilik $(\% 5,5)$ çarpıntı $(\% 2,8)$ ve kabızlık $(\% 3,7)$ sırasıyla saptanan bulgulardı.

Tanı anında hastalarımızın \%42,5'i ötiroid, \%24,5'i subklinik hipotiroidizm, \%29,2'si belirgin hipotiroidizm ve \%2,8'i subklinik hipertiroidizm tablosunda idi. Cinsiyete göre tiroid işlevleri karşılaştırıldığında subklinik hipotiroidi ve belirgin hipotiroidi sıklı̆̆ı kızlarda \%86 (n: 50) erkeklerde \%7,5 (n: 8) olarak saptandı. Hipotiroidizm sıklığı kızlarda erkeklere göre daha yüksek saptanmış olup bu fark istatistiksel olarak anlamlı idi $(p<0,05)$. Gruplar arasında yaş, cinsiyet ve guatr sıklığı açısından anlamlı fark saptanmadı (Tablo 1).

Hastalarda otoantikorlardan anti-TPO $(2-1576 \mathrm{IU} / \mathrm{mL})$ ortalama $353(\mathrm{IU} / \mathrm{mL})$, anti-TG $(4,7-7288)$ ortalama $760(\mathrm{IU} / \mathrm{mL})$ saptandı. Hipotiroidik ve ötiroidik hastalar arasında otoantikorlar açsından anlamlı fark saptanmadı $(p>0,05)$. Yine aşikar hipotiroidi ve subklinik hipotiroidisi olan gruplar arasında da otoantikor pozitifliği açısından anlamlı fark tespit edilmedi $(p>0,05)$.

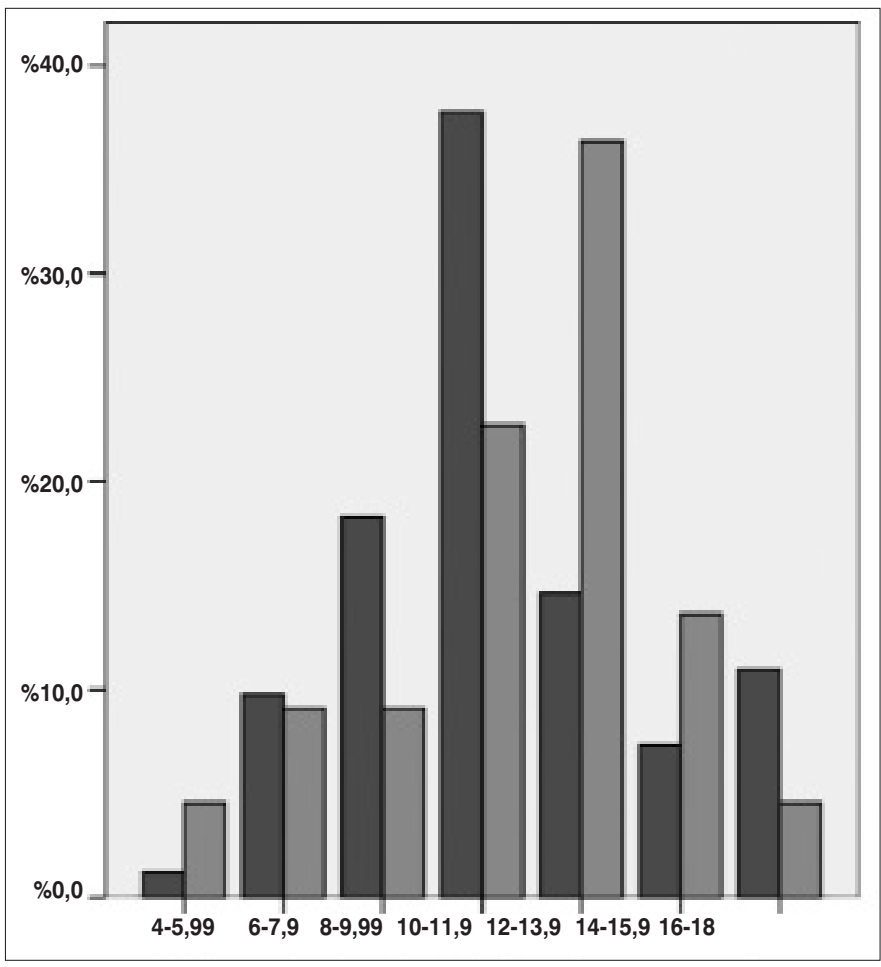

Grafik 2. Hastaların ergenlik durumuna göre dağılımı

Tablo 1. Hastaların tiroid işlevlerine göre değerlendirilmesi

\begin{tabular}{|lc|c|c|c|c|}
\hline Ötiroit $\mathbf{n : ~ 4 5 ~}$ & & Subklinik hipotiroidi $\mathbf{n : ~ 2 7}$ & Așikar hipotiroidi $\mathbf{n : ~ 3 1}$ & Subklinik hipertiroidi $\mathbf{n : ~ 3}$ & $\mathbf{p}$ \\
\hline Yaş (yIl) & $12,2 \pm 3,0$ & $11,5 \pm 2,2$ & $10,4 \pm 2,6$ & $11,4 \pm 5$ & 0,21 \\
\hline Cinsiyet kı/erkek & $30 / 15$ & $23 / 4$ & $27 / 4$ & $3 / 0$ & 0,08 \\
\hline Guatr sıklğı & $\% 51$ & $\% 62$ & $\% 70$ & $\% 100$ & 0,16 \\
\hline
\end{tabular}


Hipotiroidisi olan hastalarda tiromegali sıklığı \%67 ( $n=39)$ iken ötiroid olanlarda tiromegali \%51 ( $n=23)$ sıklıkla izlendi. Gruplar arasında istatistiksel fark saptanmadı.

Hipotiroidisi olan hastaların ortalama vücut kitle indeksleri arasında da fark saptanmadı.

Hastaların tanı anında \%81'ine tiroid ultrasonografisi yapılmış olup ( $\mathrm{n}=86$ ) bunların \%64'ü kronik tiroiditle uyumlu olup $\% 5,8$ inde nodül vardı. Hastaların \%8,7'si normal, \%3,8'inde kronik tiroidit ve nodül birlikteliği mevcuttu. Tiroid nodülü olan 10 hastanın tiroid işlevleri şöyleydi: Üçünde ötiroidi, üçünde subklinik hipotiroidi ve dördünde belirgin hipotiroidi mevcuttu. Olguların dokuz tanesine tiroid sintigrafisi yapılmış bunların beş tanesinde hiperplazik tiroid bezi, dördünde hipoaktif nodül saptanmış olup, bunlardan birinin ince iğne aspirasyon biyopsi sonucu kolloid nodül ile uyumlu bulundu.

Hastaların \%25,5'ine ( $n=27)$ ilaç başlanmamış, \%74,5'ine ( $n=79$ ) L-tiroksin başlanmış olup, ortalama tedavi süresi $23 \pm 17$ ay (1-76 ay) idi. İzlemde tiroid işlevleri en sık $(\% 52,9)$ hipotiroididen ötiroide dönmüş, ikinci sıklıkla da (\%34) ötiroidik olarak devam etmişti. Altı hastada ise iyatrojenik hipertiroidi gelişmişti.

Hastaların 28 tanesinde $(\% 26,4)$ Hashimoto tiroiditine eşlik eden başka bir otoimmün hastalık mevcuttu. Tip 1 Diyabet (DM) \%21,7 oranında en sık izlenen ek otoimmün hastalıktı. İki hastada çölyak ve DM bir arada bulunmaktaydı ve bir hastamızda da vitiligo saptandı.

Aile öykülerine bakıldığında hastaların \%35,8'inde $(n=38)$ bir tiroid hastalığı görüldü. Bunlar sırayla \%73,6 ile basit guatr, $\% 13,2$ Hashimoto, \%7,9 Graves, \%5,3 tiroid nodülü, \%2,6 guatrsız hipertiroidi idi. Ailelerde eşlik eden diğer otoimmün hastalıklara bakıldığında ise bir kişide tip 1 DM saptandı.

\section{Tartıșma}

Hashimoto tiroiditi (kronik lenfositik tiroidit) çocuk ve ergenlerde tiroidin en sık görülen hastalığı olup, aynı zamanda endemik iyot eksikliği olmayan bölgelerde kazanılmış hipotiroidi ve guatrın da önde gelen nedenidir. Hastalık artmış T hücre aktivasyonu sonucunda olup , HLA doku grupları da guatr ve tiroidit gelişimi ile ilişkilidir. HLA-DR 4 , HLA-DR 5 guatr gelişimine sebep olurken, HLADR 3 atrofik tiroiditten sorumludur (1-4).

Hastalık nadiren yaşamın ilk üç yılında görülse de, altı yaşından sonra sıklığı artar ve özellikle ergenlik döneminde en yüksek sıklığa ulaşır. Ülkemizden bildirilen çalışmalarda Demirbilek ve ark. (4) ortalama tanı yaşını 11,4 $\pm 2,97$, Yeşilkaya

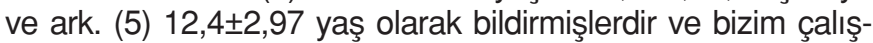
mamızda da ortalama tanı yaşı $11,5 \pm 2,8$ yıl olup literatür ile uyumlu bulunmuştur (4-5).

Hashimoto tiroiditi kızlarda 2-4 kat artmış sıklıkta izlenmekte olup, yapılan pek çok çalışmada 2,1-8,7 arasında değişen oranlar bildirilmiştir. Bizim çalışmamızda kız/erkek oranı 3,6 saptanmış olup literatürle uyumlu bulunmuştur $(3,6)$.

Guatr hastaların en sık başvuru şikayetidir (1-6), sıklığı \%40-70 arasında olup çalışmamızda da \%46 saptanmıştır. İsrail'den yapılan bir çalışmada hastaların \%40'ı guatrla başvururken \%28,9'u hipotiroidi belirtileri ile, \%12'si başka bir nedenle doktora başvurduğunda, \%10'u da otoimmünite açısından yüksek riskli grupta olup incelemeler sonucu tanı almıştır (7). Demirbilek ve ark. (4) çalışmalarında olguların \%55'inde guatr izlenirken, \%18,6'sı hipotiroidizm bulguları ile başvur- muştur (boy kısalığı, kilo fazlalığı gibi). Normal fizik muayene sırasında tanı alan hastalar ise \%11,1 oranında saptanmıştır (3). Çalışmamızda ise hastaların \%24'ü (n: 26) fizik inceleme sırasında guatr saptanarak tarafımıza yönlendirilmişti. Diğer başvuru şikayetleri sırayla boy kısalığı (\%26), kilo artışı (\%13), sinirlilik $(\% 5,5)$, çarpıntı $(\% 2,8)$ ve kabızlık $(\% 3,7)$ idi. Markoviç ve ark. (8) çalışmasında ise büyüme geriliği \%4,7, kilo artışı \%7, iştah artışı \%9,7, halsizlik \%16 ve menstrüel şikayetler \%6,7 oranında idi (8).

Tanı anında hastaların büyük kısmının tiroid işlev testleri normal ya da subklinik hipotiroidi tablosunda olup, bu hastalardaki guatr nedeni lenfositik enfiltrasyon veya tiroid dokusunu büyüten immünglobulinlerdir. Olgularımızın \%78'i subklinik hipotiroidizm veya ötiroidi tablosunda iken ülkemizden yapılan başka bir çalışmada tanı anında hastaların \%68'i, De Vies ve ark. (7) çalışmasında da hastaların \%63'ü ötiroid veya subklinik hipotiroidikti $(3,7)$.

Çalışmamızda olguların \%54'ünün hipotiroidik iken ötiroid olduğunu, \%34'ünün ise başlangıçtan itibaren ötiroid kaldığı saptandı. Hastalığın klinik seyri sırasında \%30-50 oranında kendiliğinden remisyon bildirilmiştir (2). Hacettepe Üniversitesinden yapılan bir çalışmada da ötiroid hastaların \%77'si izlemde ötiroid kalmış, hipotiroidisi olanların \%69,5'inin hipotiroidisi devam etmiş, \%30,5'inin remisyona girdiği saptanmıştır. Bu da göstermektedir ki Hashimoto tiroiditi dinamik seyirli bir hastalıktır ve olguların tiroid işlevleri aralıklı olarak izlenmelidir (9).

Otoimmün hastalıkların birlikteliğini gösteren geniş kapsamlı bir çalışmada 1419 tip1 DM’li çocuk Hashimoto hastalığı sıklığının belirlenmesi için araştırılmış ve normal topluma göre anlamlı bir şekilde artmış tiroidit sıklığı (\%3,9 iken ABD' de normal toplumdaki sıklık \%1,2) saptanmıştır (10). Bizim çalışmamızda da en sık eşlik eden otoimmün hastalık tip 1 DM olup \%21 oranında izlenmiştir. Bu sonuç, tip1 DM'li hastaların düzenli muayenelerinde guatra dikkat edilmesi ve otoantikor düzeylerinin belli aralıklarla kontrol edilmesinin gerekliliğini göstermektedir.

Tip 1 otoimmün poliglandüler sendromunun (OPS) bileşeni olarak da Hashimoto \%10 sıklıkla, tip 2 DM'de ise \%70 sıklıkla görülebilmektedir. Yine pernisiyöz anemi, alopesi, addison ve vitiligo ile birlikteliği belirlenmiştir (11). Bizim hastalarımızdan iki tanesinde çölyak hastalığı, bir tanesinde de vitiligo saptanmıştır. Bu hastaların izleminde de OPS açısından dikkatli olunmalıdır (11).

Hashimoto hastalığının sıklığı bazı kromozomal hastalıklar ile artar. Down sendromu, Klinefelter ve Turner sendromlu hastalar bu açıdan değerlendirme gerekir. Dokuz yaşında bir hastamızda Down sendromu, tip 1 DM ve Hashimoto tiroiditi birlikteliği mevcuttu. Turner sendromlu hastamız yoktu. Popva ve ark. (12) 2008'de 38 Down sendromlu çocukla yaptıkları çalışmada, hastaların 36 'sında tiroid otoantikorları yüksek saptanmış, altısında muayene ile guatr olmasına rağmen 36'sında subklinik veya belirgin hipotiroidi tespit edilmiştir (12). Bir başka çalışmada Turner sendromlu hastalarda yaşla Hashimoto hastalığının sıklığının arttığı ve normal topluma göre otoimmün hastalıkların iki kat artmış olduğu gösterilmiştir (ilk on yılda $\% 15$, üçüncü on yılda \%30) (13).

Hashimoto tiroiditi genetik yatkınlığı olan ve \%40'a varan oranlarda aile öyküsü saptanmış bir hastalıktır $(1,2)$. Markoviç ve ark. (8) çalışmalarında \%37 sıklıkla aile öyküsü saptarken, 
Sengi ve ark. (14), annelerin \%58 ve babaların \%26 oranında etkilendiğini bildirmişlerdir. Bizim çalışmamızda da ailelerde \%21 oranında otoimmün tiroit hastalığı saptanmıştır.

Tanı için tiroid ultrasonografisi gerekmemekle birlikte yapıldığında hipoekoik, yaygın, büyük, dokusu heterojen özellik gösteren tiroid bezi saptanır (7). Hastalarımızın tanı anında $\% 81$ 'ine tiroid ultrasonografisi yapılmış olup (n: 86), bunların $\% 64$ 'ünde kronik tiroiditle uyumlu bulgular saptanmıştır.

İzlemde nodül gelişen ve tedavi ile gerilemeyen hastalara ince iğne aspirasyon biyopsisi yapılmalıdır. Demirbilek ve ark. (4) çalışmasında bir hastada tiroidin papiller kanseri saptanmış olup cerrahi uygulanmıştır. Hastalarımızın nodülleri en büyük 5 $\mathrm{mm}$ olup izlemde ya kaybolmuş ya da boyutu artmamıştı. Nodülü gerilemeyen veya nodül çapı $1 \mathrm{~cm}$ 'nin üzerinde bulunan hastamız olmadığı için hiçbir hastamıza iğne aspirasyon biyopsisi yapılmadı, ancak bir hastamızın ilaçla guatrı küçülmediği için dış görünüm kaygısından ötürü cerrahiye yönlendirildi ve histopatolojik değerlendirilmesinde kronik lenfositik tiroiditle uyumlu saptandı. Hashimoto tiroiditinde sintigrafide hipoaktif nodüller olabileceği de bilinmektedir (7).

Filipoviv ve ark. (15) lenfositik tiroiditin, tiroid kanser gelişiminde ve geliştikten sonra da yayılımı ve kan yoluyla metastazlarda risk etmeni olduğunu göstermişlerdir (15). Hashimoto hastalığının en önemli komplikasyonlarınadan biri lenfomadır (16-20). Kore'den yapılan erişkinleri içeren bir çalışmada 44 tiroid lenfomalı olgunun \%56'sında malinite Hashimoto tiroidit zemininde gelişmiştir. Hastalarımızın ise hiç biri lenfoma ve papiller kanser tanısı almamıştır (16).

Sonuç olarak otoimmüniteden kaynaklanan ve yaşla sıklığı artan Hashimoto tiroiditinde belli aralıklarla tiroit işlev testleri değerlendirilmeli, tiroit lenfoması ve tiroit papiller kanserinin nadir de olsa eşlik edebileceği unutulmamalıdır.

\section{Çıkar çatışması: Bildirilmedi.}

\section{Kaynaklar}

1. La Frachi S. Disorders of tyhroid gland. In: Kliegman R, Behrman R, Jenson $\mathrm{H}$, Stanton B, (eds). Nelson texbook of pediatrics. 18th. ed. Elsevier: Saunders, 2008; 2327-8.

2. Fisher DA, Grueters A. Thyroid disorders in childhood and adolescents. In: Sperling MA, (ed). Pediatric endocrinology. 3rd ed. Elsevier: Saunders, 2008; 236-8.

3. Weetman AP, McGregor AM. Autoimmune thyroid disease: further developments in our understanding . Endocr Rev 1994; 15: 788-830.
4. Demirbilek H, Kandenir N, Gönç EN, et al. Hashimoto's thyroiditis in children and adolescent: a retrospective study on clinical, epidemiological and laboratory properties of the disease. J Pediatr Endocrinol Metab 2007; 20: 1195-205.

5. Yeşilkaya $E$, Belen B, Bideci A, ve ark. Kronik otoimmün tiroiditli çocuk ve ergenlerin klinik özellikleri. Gülhane Tıp Dergisi 2008; 50: 147-50.

6. Pearce EN, Farwell AP, Braverman LE. Throiditis. N Engl J Med 2003; 348: 2646-55.

7. L de Vries, S Bulvik, M Phillip. Chronic autoimmune thyroiditis in children and adolescents: at presentation and during long-term follow-up. Arch Dis Child 2009; 94: 33-7.

8. Markovic S, Kostic G, Igrutinovic Z, et al. Hashimoto disease in children and adolescent. Srp Arch Celok 2008; 136: 262-6.

9. Demirbilek H, Kandemir N, Gonç EN, et al. Assessment of thyroid function during the long course of Hashimoto's thyroiditis in children and adolescents. Clin Endocrinol 2009; 71: 451-4.

10. Radetti, Gottardi E, Bona G et al. Study Group of Thyroid Disease of the Italian Society for Pediatric Endocrinology and Diabetes (SIEDP/ISPED). The natural history of euthyroid Hashimatos thyroiditis in children. J Pediatr 2006; 149: 827-32.

11. Türkoğlu Z, Kavala M, Kolcak O. Autoimmun polyglanduler syndrome -3 in a child. Dermatol online J. 2010; 15: 8.

12. Popava G, Paterson WF, Brown A, Donaldson MD. Hashimoto's thyroiditis in Down's syndrome: clinical presentation and evolution. Horm Res 2008; 70: 278-84.

13. Jorgensen KT, Rostgaard K, Bache I, et al. Autoimmune diseases in women with Turner's syndrome. Arthiritis Rheum 2010; 62: 658-66.

14. Segni M, Wood J, Pucarelli I, et al. Clustering of autoimmune thyroid diseases in children and adolescents: a study of 66 families. J Pediatr Endocrinol Metab 2001; 14: 1271-5.

15. Filipoviç A, Paunoviç I, Vuckoviç Li. Influence of lymphocitic thyroiditis on prognostic outcome differentiated thyroid carcinoma. Acta Chir Lugosl. 2010; 57: 85-94.

16. Hwang YC, Kim TY, Kim WB, et al. Clinical characteristics of primary thyroid lymphoma in Koreans. Endocr J 2009; 56: 399-405.

17. Rother KI, Zimmerman D, Schwenk WF. Effect of thyroid hormone treatment on thyromegaly in children with Hashimoto disease. J Pediatr 1994; 124: 599-601.

18. Comotis R, Faucher L, Lafleche L. Outcome of hypothyroidism caused by Hashimoto's thyroiditis. Arch Intern Med 1995; 155: 1441-8.

19. Garcia CJ, Daneman A, Thorner P, et al. Sonography of multinodular thyroid galnd in children and adolescents. Am J Dis Child 1992; 146: 811-6.

20. Hung W, Anderson KD, Chandra RS, et al. Solitary thyroid nodules in 71 children and adolescents. J Pediatr Surg 1992; 27: 1407-9.

21. Hung W. Solitary thyroid nodules in 93 children and adolescents. A 35-years experience. Horm Res. 1999; 52: 15-8. 